\title{
Outcomes, quality of life, and survival after esophagectomy for squamous cell carcinoma: A propensity score-matched comparison of operative approaches
}

Hao Wang, MD, Yaxing Shen, MD, Mingxiang Feng, MD, Yi Zhang, MD, Wei Jiang, MD, Songtao $\mathrm{Xu}, \mathrm{MD}$, Lijie Tan, MD, and Qun Wang, MD

\begin{abstract}
Background: Minimally invasive esophagectomy (MIE) theoretically offers advantages compared with open esophagectomy (OE). However, the long-term outcomes have not been well studied, especially for esophageal squamous cell carcinoma. We retrospectively compared postoperative outcomes, quality of life (QOL), and survival in a matched population of patients undergoing MIE, with a control (OE) group.
\end{abstract}

Methods: From May 2004 to August 2013, MIE was performed for a group of 735 patients, which was compared with a group of 652 cases of OE. Eventually, 444 paired cases, matched using propensity-score matching, were selected for further statistical analysis.

Results: Compared with the OE group, the MIE group had shorter operation duration ( $191 \pm 47$ minutes vs 211 \pm 44 minutes, $P<.001)$; less blood loss $(135 \pm 74 \mathrm{ml}$ vs $163 \pm 84 \mathrm{ml}, P<.001)$; similar lymph node harvest (24.1 \pm 6.2 vs $24.3 \pm 6.0, P=.607$ ); shorter postoperative hospital stay (11 days [range: 7-90 days] vs 12 days [range: $8-112$ days], $P<.001)$; fewer major complications $(30.4 \%$ vs $36.9 \%, P=.039)$; a lower readmission rate to the intensive-care unit (5.6\% vs $9.7 \%, P=.023)$; and similar perioperative mortality $(1.1 \%$ vs $2.0 \%$, $P=.281$ ). At a median follow-up of 27 months, the 2-year overall survival rates in the MIE and OE group were: (1) stage 0 and I: $92 \%$ versus $90 \%(P=.864)$; (2) stage II: $83 \%$ versus $82 \%(P=.725)$; (3) stage III: $59 \%$ versus $55 \%(P=.592)$; $(4)$ stage IV: $43 \%$ versus $43 \%(P=.802)$. The generalized estimating equation analysis showed that MIE had an independently positive impact on patients' postoperative QOL.

Conclusions: In our experience, MIE is a safe and effective procedure for the treatment of esophageal squamous cell carcinoma. It may offer better perioperative outcomes, better postoperative QOL, and equal oncologic survival, compared with OE. (J Thorac Cardiovasc Surg 2015;149:1006-15)

See related commentary on pages 1016-7.

Supplemental material is available online.

Although traditional open esophagectomy (OE) offers a potential cure for esophageal cancer, it is associated with high perioperative morbidity and mortality. Recently, minimally invasive esophagectomy (MIE) has become the

\footnotetext{
From the Division of Thoracic Surgery, Zhongshan Hospital, Fudan University, Shanghai, People's Republic of China.

Disclosures: Authors have nothing to disclose with regard to commercial support.

Y. Shen contributed equally to this work.

Read at the 94th Annual Meeting of The American Association for Thoracic Surgery, Toronto, Ontario, Canada, April 26-30, 2014.

Received for publication April 24, 2014; revisions received Nov 26, 2014; accepted for publication Dec 25, 2014; available ahead of print March 7, 2015.

Address for reprints: Lijie Tan, MD, Division of Thoracic Surgery, Zhongshan Hospital, Fudan University, 180 Fenglin Rd, Shanghai, People's Republic of China (E-mail: tan.lijie@zs-hospital.sh.cn).

$0022-5223 / \$ 36.00$

Copyright (c) 2015 by The American Association for Thoracic Surgery

http://dx.doi.org/10.1016/j.jtcvs.2014.12.063
}

recommended approach, popularized in centers with experienced surgeons. ${ }^{1}$ Theoretically, MIE offers advantages, compared with conventional $\mathrm{OE}$, and has been preliminarily shown to provide benefits in perioperative outcomes. Nevertheless, the long-term efficacy of MIE compared with $\mathrm{OE}$ has not been well studied, especially for esophageal squamous cell carcinoma (ESCC), which is quite different from esophageal adenocarcinoma in terms of area of prevalence, tumor location, biological behavior, and prognosis.

We started our practice of MIE in 2004 and have performed more than 700 such procedures, most of which were for ESCC. Thus, we retrospectively studied postoperative outcomes, quality of life (QOL), and cancer survival in a matched population of patients undergoing MIE, with a control (OE) group.

\section{MATERIALS AND METHODS Patients}

From May 2004 to August 2013, patients with ESCC were enrolled in this study. All patients underwent esophagogastroduodenoscopy and were given a diagnosis of pathologic disease. Imaging examinations, including thoracoabdominal, enhanced computed tomography, cervical ultrasonography, and endoscopic ultrasonography (as well as positron 


\section{Abbreviations and Acronyms \\ cTis $=$ Clinical Trials Information System \\ cTNM $=$ clinical tumor-node-metastasis \\ ESCC $=$ esophageal squamous cell carcinoma \\ MIE = minimally invasive esophagectomy \\ $\mathrm{OE}=$ open esophagectomy \\ pTNM $=$ pathologic tumor-node-metastasis \\ $\mathrm{QOL}=$ quality of life}

emission tomography, if possible), were used to determine the clinical stage.

For patients with cTis $3 \mathrm{~N} 1 \mathrm{M} 0$ or more-advanced disease, neoadjuvant therapy was performed. The treatment was determined by a multidisciplinary team. For patients with a cTis 3 N0 M0 classification (including cases that were down-staged after neoadjuvant therapy), surgery was performed after risk assessment. Patients chose which procedure (MIE or OE) to undergo, during the preoperative interview. The CONSORT (Consolidated Standards of Reporting Trials) flow diagram is shown in Figure 1. The institutional review board of Zhongshan Hospital, Fudan University approved the use of a prospectively maintained database of patients with esophageal carcinoma for this retrospective study (No. 2013154).

\section{Surgical Procedures}

Anesthesia and ventilation. All patients received a combination of epidural ( $0.1875 \%$ bupivacaine and morphine) and general anesthesia (inhaled sevoflurane) during the operation. For the OE group, patients were intubated with a left-side double-lumen endotracheal tube and single-lung ventilation. The intraoperative, mechanical ventilation parameters were set to a tidal volume of $8 \mathrm{ml} / \mathrm{kg}$. For the MIE group, intubation and ventilation were the same as in the OE group, early on ${ }^{2}$; later, however, we adopted a single-lumen endotracheal tube and double-lung ventilation with a tidal volume of 6 to $8 \mathrm{ml} / \mathrm{kg}$, which was assisted by an artificial $\mathrm{CO}_{2}$ pneumothorax at $8 \mathrm{~mm} \mathrm{Hg}$.

Surgical position. For the MIE group, initially, patients were placed in the left lateral decubitus position. The surgeon and 2 assistants stood on either side of the patient, and 4 thoracoscopic ports of approximately 0.5 to $1.2 \mathrm{~cm}$ were placed on the thoracic cavity. Details are described in our previous publication. ${ }^{3}$ Afterward, we adopted the prone position for patients, and then the semiprone position, for better surgical exposure and operative ergonomics. The surgeon and 1 assistant stood on the ventral side of the patient, and 4 ports were used. ${ }^{2}$ For the OE group, patients were placed in the left lateral decubitus position.

Operation procedures. In the MIE group, for the majority of cases (in which the tumor was located in the thoracic esophagus), the procedures consisted of the following 3 stages: (1) mobilization of the intrathoracic esophagus and dissection of the intrathoracic lymph node by thoracoscopy; (2) mobilization of the stomach, with dissection of the celiac lymph node via laparotomy (mainly in the early period) or laparoscopy; and (3) resection of the tumor, pulling up of the gastric conduit, and gastroesophageal reconstruction with cervical anastomosis. For the tumors located in the upper esophagus, cervical lymphadenectomy was performed. For the other cases (in which the tumor was located in the abdominal esophagus), the procedures comprised the following 2 stages: (1) mobilization of the stomach, with dissection of the celiac lymph node via laparoscopy; and (2) mobilization of the intrathoracic esophagus and dissection of the intrathoracic lymph node via thoracoscopy, pulling up of the gastric conduit, resection of the tumor, and gastroesophageal reconstruction with intrathoracic anastomosis. Details of the techniques are described elsewhere. ${ }^{2,4}$ In the OE group, the procedure involved open Ivor-Lewis esophagectomy and open Ivor-Lewis McKeown esophagectomy.

Mediastinal lymphadenectomy. In the early period (before June 2009), conventional lymphadenectomy was performed for the dissection of the subcarinal and paraesophageal lymph nodes. Later, we added the extensive lymphadenectomy along the bilateral recurrent laryngeal nerves, which had been our regular procedure. Details of the techniques are described elsewhere.

Perioperative management. Milk was administered to patients orally, 6 hours before surgery, which facilitated visualization of the thoracic duct, thereby minimizing the risk of it sustaining iatrogenic injury during MIE. ${ }^{6}$ Postoperatively, epidural analgesia was used until the thoracic drainage was removed (within approximately 3-5 days). A feeding jejunostomy was established in all cases, and enteral nutrition was started on postoperative day 1. An examination of the patient's water-soluble swallow was performed on postoperative day 7 , before oral feeding was started.

\section{Follow-up}

Patients were evaluated at regular intervals: every 3 months in the first year, and every 6 months beginning in the second year. Follow-up investigations included clinical examinations, evaluation of the biochemistry of tumor-marker (carcino-embryonic antigen, squamous cell carcinoma-related antigen, etc) levels, CT scanning of the thorax and abdomen, and gastroendoscopy whenever indicated.

\section{Health-Related Quality-of-Life Assessment}

The assessment of health-related QOL was based on a previously validated questionnaire, QLQ-C30 (version 3.0; quality-of-life questionnaire), combined with an esophageal cancer-specific module, QLQ-OES18, which were developed by the European Organization for Research and Treatment of Cancer. ${ }^{7}$ That organization's questionnaire includes: 1 global QOL scale; 5 functional scales (physical, role, emotional, cognitive, and social); and 19 symptom scales (fatigue, nausea and vomiting, pain, dyspnea, insomnia, appetite loss, constipation, diarrhea, financial difficulties, dysphagia, eating, reflux, esophageal pain, swallowing saliva, choking when swallowing, dry mouth, taste problem, coughing and speech problem). After obtaining informed consent from the patients, we asked them to complete the questionnaires, before the operation and at multiple follow-up intervals $(1,3,6,12,18$, and 24 months postoperatively), via mail, in-person visit, or outpatient consultation.

\section{Data Collection and Statistical Analysis}

Clinical data for all cases were collected from the prospectively maintained database at our institution. The pathologic classification was made according to the Union for International Cancer Control esophageal cancer TNM (tumor-node- metastasis) staging system (6th edition). All collected data were tabulated using Microsoft Excel (Microsoft, Redmond, Wash) for further analysis.

Statistical analyses were performed according to the intent-to-treat principle. To control for potential differences in the characteristics of patients between the 2 groups, the method of propensity-score matching was used. By using a logistic regression model, which included variables such as age, gender, body mass index, Charlson Comorbidity Index, ASA (American Society of Anesthesiologists) grade, tumor location, cTNM (clinical) stage, neoadjuvant therapy, pTNM (pathologic) stage, and historical period of surgery, propensity scores were computed as the conditional probability of receiving cases, via either MIE or OE. Using the nearest neighbor-matching algorithm, we created propensity score-matched pairs without replacement (a 1:1 match). The caliper 
Patients with ESCC ( $\mathrm{n}=6319)$

Physical and Imaging

Examinations

$\downarrow$

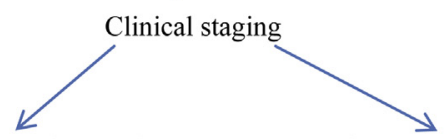

cTis-3N0M0 (n=3398)

cTis-3N1M0 or more advanced $(\mathrm{n}=2921)$
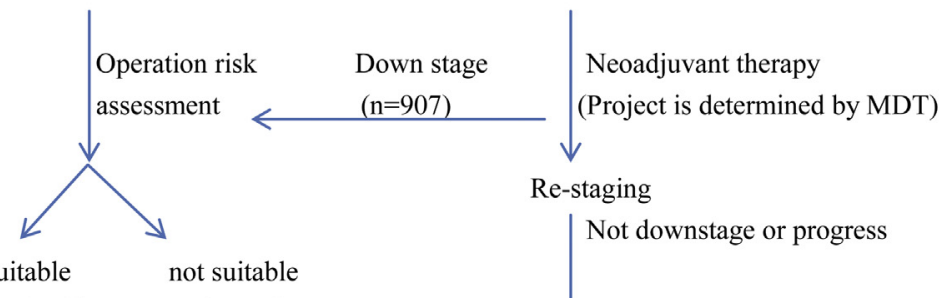

$(\mathrm{n}=3752)$

$(\mathrm{n}=553)$

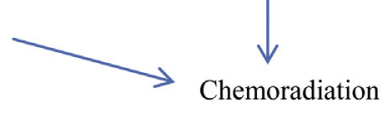

Surgery

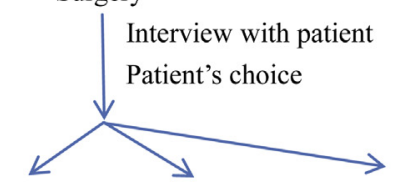

MIE team OE team other surgical treatment (Sweet esophagectomy, transhital, ESD, etc)<smiles>[As][As]</smiles>

$(\mathrm{n}=2365)$

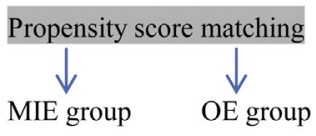

$(n=444) \quad(n=444)$

FIGURE 1. The CONSORT (Consolidated Standards of Reporting Trials) flow diagram. ESCC, Esophageal squamous cell carcinoma; $M D T$, multidisciplinary team; $M I E$, minimally invasive esophagectomy; $O E$, open esophagectomy; $E S D$, endoscopic submucosal dissection.

definition was set at 0.02 . Eventually, 444 paired cases were matched from the cohort, and the 2 groups were comparable in patient characteristics (Table 1 and Table E1).

Statistical analysis was undertaken using SPSS 22.0 (SPSS Inc, Chicago, Ill). Variables were compared using the Mann-Whitney $U$ test, the Student $t$ test, $\chi^{2}$ analysis, and the Fisher exact test. Survival curves based on the TNM classification were estimated using the Kaplan-Meier method, and the significance of between-group differences was assessed with the log-rank test. Scores from the QOL assessment, which were derived from the questionnaires, were linearly transformed into a 0-to-100 scale according to the European Organization for Research and Treatment of Cancer Scoring Manual. Higher scores for the categories of global QOL and physical function represent a higher QOL status, whereas higher scores for the fatigue, pain, and dyspnea categories indicate a lower QOL status. We used a generalized estimating equation to do the longitudinal data analysis, to determine the effective impact of correlative factors on postoperative QOL, including age, gender, body mass index, Charlson Comorbidity Index, ASA grade, tumor location, neoadjuvant therapy, cTNM stage, pTNM stage, historical period of surgery, surgical approach, and length of postoperative time period. The analysis was done using R 3.0.1.

\section{RESULTS}

\section{Operative Features}

In 735 cases, MIE was performed, with conversion to thoracotomy in 8 patients (in 2 because of bleeding, in 5 because of technical difficulty, and in 1 because of tracheal injury). The operative features of the patients are described in Table 2. Compared with the OE group, the MIE group had shorter operation duration, less blood loss, and a shorter postoperative length of hospital stay; the 2 groups had similar lymph node harvest.

\section{Morbidity and Mortality}

The rate of total complications (based on the Common Terminology Criteria for Adverse Events) was similar in the 2 groups (Table 2). However, the MIE group had fewer major complications $(30.4 \%$ vs $36.9 \%, P=.039)$, especially respiratory complications $(8.6 \%$ vs $13.3 \%$, 
TABLE 1. Patient demographics

\begin{tabular}{|c|c|c|c|c|c|c|}
\hline \multirow[b]{2}{*}{ Variable } & \multicolumn{2}{|c|}{ Before matching } & \multirow[b]{2}{*}{$P$ value } & \multicolumn{2}{|c|}{ After matching } & \multirow[b]{2}{*}{$P$ value } \\
\hline & $\operatorname{MIE}(n=735)$ & OE $(n=652)$ & & $\operatorname{MIE}(n=444)$ & OE $(n=444)$ & \\
\hline Age, median (y [IQR]) & $56(32-83)$ & $57(34-77)$ & .872 & $56(32-77)$ & $56(38-76)$ & .531 \\
\hline Sex (male/female) & $603 / 132$ & $529 / 123$ & .664 & $362 / 82$ & $358 / 86$ & .732 \\
\hline $\mathrm{BMI}$, mean $\pm \mathrm{SD}$ & $22.3 \pm 2.4$ & $22.1 \pm 2.9$ & .359 & $22.2 \pm 2.4$ & $22.1 \pm 2.9$ & .519 \\
\hline $\mathrm{CCI}$ & & & .511 & & & .220 \\
\hline 0 & 3 & 2 & & 1 & 1 & \\
\hline 1 & 43 & 33 & & 23 & 27 & \\
\hline 2 & 233 & 235 & & 181 & 158 & \\
\hline 3 & 274 & 246 & & 156 & 191 & \\
\hline 4 & 157 & 121 & & 70 & 52 & \\
\hline 5 & 22 & 13 & & 11 & 13 & \\
\hline 6 & 3 & 2 & & 2 & 2 & \\
\hline ASA grade & & & .873 & & & .812 \\
\hline I & 492 & 443 & & 321 & 328 & \\
\hline II & 215 & 187 & & 107 & 99 & \\
\hline III & 28 & 22 & & 16 & 17 & \\
\hline Tumor location & & & .995 & & & .657 \\
\hline Upper & 106 & 95 & & 63 & 68 & \\
\hline Middle & 412 & 364 & & 244 & 251 & \\
\hline Lower & 217 & 193 & & 137 & 125 & \\
\hline Neoadjuvant therapy & & & .335 & & & .878 \\
\hline Chemoradiotherapy & 84 & 90 & & 58 & 53 & \\
\hline Chemotherapy & 36 & 36 & & 22 & 22 & \\
\hline None & 615 & 526 & & 364 & 369 & \\
\hline cTNM stage & & & .342 & & & .898 \\
\hline Tis N0 M0 & 25 & 19 & & 15 & 15 & \\
\hline T1 N0 M0 & 99 & 70 & & 49 & 56 & \\
\hline T2 N0 M0 & 448 & 402 & & 271 & 269 & \\
\hline T3 N0 M0 & 163 & 161 & & 109 & 104 & \\
\hline pTNM stage & & & .272 & & & .710 \\
\hline $0 \& \mathrm{I}$ & 121 & 85 & & 62 & 69 & \\
\hline II & 427 & 384 & & 254 & 255 & \\
\hline III & 149 & 142 & & 100 & 99 & \\
\hline IV & 38 & 41 & & 28 & 21 & \\
\hline
\end{tabular}

$P$ values were computed using $\chi^{2}$ analysis, except for the following: age, Mann-Whitney $U$ test; gender (in addition to $\chi^{2}$ analysis) and body mass index, Student $t$ test; CCI (after matching), Fisher exact test. Values for cTNM stage include cases of down-staging after neoadjuvant therapy. MIE, Minimally invasive esophagectomy; $O E$, open esophagectomy; IQR, interquartile; BMI, body mass index; CCI, Charlson Comorbidity Index; ASA, American Society of Anesthesiologists; $c T N M$, clinical tumor-nodemetastasis; $p T N M$, pathologic tumor-node-metastasis; $S D$, standard deviation.

$P=.024)$ (Table 3). To treat the major complications, reoperation was needed for $3(0.7 \%)$ cases in the MIE group and $8(1.8 \%)$ cases in the OE group. In addition, readmission to the intensive-care unit occurred less in the MIE than in the OE group (5.6\% vs $9.7 \%, P=.023)$. As a result, the perioperative mortality was similar in the 2 groups after matching $(1.1 \%$ vs $2.0 \%, P=.281)$ (Table 4).

\section{Survival}

At a median follow-up of 27 months, the 2-year overall survival rates based on pathologic stage in the MIE and OE group, respectively, were: (1) stage 0 and I: $92 \%$ versus $90 \%(P=.864)$; (2) stage II: $83 \%$ versus $82 \%(P=.725)$;
(3) stage III: $59 \%$ versus $55 \%(P=.592)$; (4) stage IV: $43 \%$ versus $43 \%(P=.802)$. No statistical difference was found on the survival curves for each pathologic stage between the 2 groups (Figures 2-5).

\section{Health-Related Quality of Life}

At the baseline level before operation, the scores on all scales were similar in the 2 groups, with no statistically significant difference. Postoperatively, the patients in the MIE group had higher scores for the physical function category, but lower scores for the fatigue, pain, and dyspnea categories, compared with the OE group. Consistent with this result, the scores on global QOL were higher in the MIE group than in the OE group, especially in the first 
TABLE 2. Comparison of operative features (after matching)

\begin{tabular}{lccr}
\hline \multicolumn{1}{c}{ Variable } & MIE $(\mathbf{n}=\mathbf{4 4 4})$ & OE $(\mathbf{n}=\mathbf{4 4 4})$ & $\boldsymbol{P}$ value \\
\hline Operation duration (min) & $191 \pm 47$ & $211 \pm 44$ & $<.001$ \\
Blood loss (ml) & $135 \pm 74$ & $163 \pm 84$ & $<.001$ \\
Number of lymph nodes & $24.1 \pm 6.2$ & $24.3 \pm 6.0$ & .607 \\
$\quad$ harvested (n) & & & \\
Length of ICU stay (d) & $1(0-30)$ & $1(0-39)$ & .407 \\
Length of postoperative & $11(7-90)$ & $12(8-112)$ & $<.001$ \\
$\quad$ hospital stay (d) & & & \\
Total no. complications (\%) & $230(51.8)$ & $254(57.2)$ & .106 \\
$\quad$ Grade 1-2 & 95 & 90 & \\
$\quad$ Grade 3 & 112 & 123 & \\
$\quad$ Grade 4 & 23 & 41 & \\
\hline
\end{tabular}

$P$ values were computed by Student $t$ test, except for: both length-of-stay categories (Mann-Whitney $U$ test); and complications. Complications (Chi-square tests) were graded according to the Common Terminology Criteria for Adverse Events. MIE, Minimally invasive esophagectomy; $O E$, open esophagectomy; $I C U$, intensive-care unit.

year of survival. Furthermore, the result of the generalized estimating equation analysis showed that the surgical approach (MIE vs OE) and the length of the postoperative time period independently had a positive impact on patients' postoperative QOL (global QOL, physical function, fatigue symptoms, pain symptoms, and dyspnea symptoms), whereas age and neoadjuvant chemotherapy independently had a negative impact on global QOL (Table 5 and Tables E2 and E3).

TABLE 3. Comparison of major complications (after matching)

\begin{tabular}{lccr}
\hline \multicolumn{1}{c}{ Variable } & $\begin{array}{c}\text { MIE } \\
(\mathbf{n}=\mathbf{4 4 4})\end{array}$ & $\begin{array}{c}\text { OE } \\
(\mathbf{n}=\mathbf{4 4 4})\end{array}$ & $\begin{array}{c}\boldsymbol{P} \\
\text { value }\end{array}$ \\
\hline Respiratory complications & $38(8.6)$ & $59(13.3)$ & .024 \\
Pneumonia & $29(6.5)$ & $44(9.9)$ & \\
ARDS & $9(2.0)$ & $15(3.4)$ & \\
Circulatory complications & $7(1.6)$ & $15(3.4)$ & .084 \\
Heart failure & $3(0.7)$ & $7(1.6)$ & \\
Myocardial infarction & $1(0.2)$ & $3(0.7)$ & \\
Pulmonary embolism & $1(0.2)$ & $2(0.5)$ & \\
Severe arrhythmia & $1(0.2)$ & $1(0.2)$ & \\
Cerebrovascular accident & $1(0.2)$ & $2(0.5)$ & \\
Digestive complications & $60(13.5)$ & $50(11.3)$ & .308 \\
Cervical anastomotic leak & $52(11.7)$ & $29(6.5)$ & \\
Intrathoracic gastric conduit & $4(0.9)$ & $15(3.4)$ & \\
$\quad$ necrosis or intrathoracic & & & \\
anastomotic leak & & & \\
Delayed gastric emptying & $4(0.9)$ & $6(1.4)$ & \\
Operation-related complications & $30(6.3)$ & $40(8.8)$ & .213 \\
Postoperative bleeding & $1(0.2)$ & $2(0.5)$ & \\
Chylothorax & $2(0.5)$ & $3(0.7)$ & \\
Hoarseness & $26(5.9)$ & $28(6.3)$ & \\
Tracheal injury & $1(0.2)$ & $1(0.2)$ & \\
Wound infection & 0 & $6(1.4)$ & \\
Total major complications & $135(30.4)$ & $164(36.9)$ & .039 \\
\hline
\end{tabular}

Values are $\mathrm{n}(\%) . P$ values were computed using $\chi^{2}$ analysis. MIE, Minimally invasive esophagectomy; $O E$, open esophagectomy; $A R D S$, acute respiratory distress syndrome.
TABLE 4. Intervention for major complications and mortality

\begin{tabular}{lccr}
\hline \multicolumn{1}{c}{ Variable } & $\begin{array}{c}\text { MIE } \\
(\mathbf{n = 4 4 4 )}\end{array}$ & $\begin{array}{c}\text { OE } \\
(\mathbf{n}=\mathbf{4 4 4})\end{array}$ & $\begin{array}{c}\boldsymbol{P} \\
\text { value }\end{array}$ \\
\hline Reoperation (total) & $3(0.7)$ & $8(1.8)$ & .129 \\
Surgical hemostasis & 1 & 2 & \\
Ligation of thoracic duct & 1 & 2 & \\
Tracheal repair & 1 & 1 & \\
Debridement and suturing & 0 & 3 & \\
Readmission to ICU & $25(5.6)$ & $43(9.7)$ & .023 \\
Perioperative mortality & $5(1.1)$ & $9(2.0)$ & .281 \\
\hline
\end{tabular}

Values are $\mathrm{n}(\%) . P$ values were computed using $\chi^{2}$ analysis. MIE, Minimally invasive esophagectomy; $O E$, open esophagectomy; $I C U$, intensive-care unit.

\section{DISCUSSION}

This retrospective study involved a comprehensive comparison of MIE versus OE in a matched population of ESCC patients, which showed that the MIE group had better perioperative features, better postoperative QOL, and equal oncologic survival. An increasing number of institutions are using MIE in clinical practice. Luketich and colleagues ${ }^{1}$ published the largest volume of MIE procedures (ESCC: $11 \%$; adenocarcinoma: $76 \%$ ). Conversion to open surgery was required for $4.5 \%$ of the patients. The median number of lymph nodes resected was 21 ; the length of stay was 8 days (range: 6-14 days), and the intensive-care unit stay was 2 days (range: 1-3 days). The major morbidity was $26.4 \%$, and the 30 -day mortality was $1.7 \%$.

The feasibility of MIE has been confirmed in several other large case reports. ${ }^{8-10}$ However, the pathologic type in these cases is mainly adenocarcinoma in the distal esophagus or gastroesophageal junction. Nevertheless, our study showed that MIE is equally suitable for treating ESCC that is located mainly in the middle region of the esophagus.

Growing evidence suggests that MIE could provide equal-quality or better operative features compared with open surgery. ${ }^{11-16}$ Biere and colleagues ${ }^{17}$ conducted a multicenter randomized controlled trial, lending weight to their findings comparing MIE $(\mathrm{n}=59)$ with OE $(\mathrm{n}=56)$ in the treatment of esophageal cancer (ESCC: 37.4\%; adenocarcinoma: $61.7 \%$ ). The results showed that MIE, versus $\mathrm{OE}$, resulted in a longer operation duration (329 minutes [range: 90-559 minutes] vs 299 minutes [range: $66-570$ minutes], $P=.002)$; less blood loss (200 $\mathrm{ml}$ [range: $20-1200 \mathrm{ml}$ ] vs $475 \mathrm{ml}$ [range: $50-3000 \mathrm{ml}$ ], $P<.001$ ); a shorter hospital stay (11 days [range: 7-80 days] vs 14 days [range: $1-120$ days], $P=.044$ ); less pulmonary infection in the first 2 weeks $(9 \%$ vs $29 \%$, $P=.005)$ and in-hospital (12\% vs $34 \%, P=.005)$. No statistically significant difference was found for other morbidities, or for mortality (3\% [MIE] vs $2 \%$ [OE], $P=.590$ ). These findings are similar to those in our series on ESCC cases, confirming the advantage of MIE in regard to perioperative outcomes. 
TABLE 5. Analysis of QOL (generalized estimating equation)

\begin{tabular}{|c|c|c|c|c|c|c|c|c|c|c|}
\hline & \multicolumn{2}{|c|}{ Global QOL } & \multicolumn{2}{|c|}{ Physical function } & \multicolumn{2}{|c|}{ Fatigue symptoms } & \multicolumn{2}{|c|}{ Pain symptoms } & \multicolumn{2}{|c|}{ Dyspnea symptoms } \\
\hline & Estimation & $P$ value & Estimation & $P$ value & Estimation & $P$ value & Estimation & $P$ value & Estimation & $P$ value \\
\hline Intercept & -20.946 & $<.001$ & -32.937 & $<.001$ & 24.927 & $<.001$ & 38.952 & $<.001$ & 13.736 & $<.001$ \\
\hline Age & -0.205 & .015 & -0.079 & .186 & 0.076 & .314 & -0.012 & .820 & 0.025 & .483 \\
\hline Sex & -0.234 & .712 & -0.232 & 639 & -0.306 & .627 & -0.618 & .160 & -0.467 & .099 \\
\hline BMI & -0.117 & .226 & -0.054 & .474 & 0.016 & .841 & -0.027 & .654 & 0.056 & .166 \\
\hline $\mathrm{CCI}$ & 0.572 & .205 & -0.035 & .924 & -0.068 & .871 & 0.136 & .647 & -0.444 & .028 \\
\hline ASA grade & -0.817 & .266 & -0.519 & .383 & 0.383 & .583 & 0.181 & .706 & 1.170 & $<.001$ \\
\hline Tumor location (U) & 0.086 & .909 & 0.391 & .501 & -0.028 & .965 & 0.148 & .783 & 0.622 & .076 \\
\hline Tumor location (M) & 0.620 & .260 & 0.306 & .486 & 0.066 & .900 & -0.437 & .237 & -0.004 & .989 \\
\hline Neoadjuvant chemotherapy & -2.858 & .016 & -1.119 & .292 & 1.850 & .070 & 1.436 & .064 & -0.112 & .839 \\
\hline Neoadjuvant chemoradiotherapy & 0.302 & .750 & 0.571 & .417 & -0.690 & .489 & -0.538 & .370 & 0.137 & .730 \\
\hline cTNM stage & 0.918 & .180 & 0.675 & .194 & 0.664 & .315 & 0.087 & .858 & 0.515 & .142 \\
\hline pTNM stage & -0.712 & .279 & -0.321 & .484 & -0.299 & .603 & 0.413 & .335 & -0.255 & .430 \\
\hline Historical period of surgery & -0.349 & .537 & -0.228 & .590 & 0.227 & .682 & 0.511 & .194 & -0.133 & .634 \\
\hline Surgical approach & 19.506 & $<.001$ & 21.742 & $<.001$ & -10.599 & $<.001$ & -21.537 & $<.001$ & -6.677 & $<.001$ \\
\hline Length of postoperative time & 1.656 & $<.001$ & 1.624 & $<.001$ & -1.292 & $<.001$ & -1.567 & $<.001$ & -0.221 & $<.001$ \\
\hline
\end{tabular}

Bold indicates statistical significance $(P<.05)$. QOL, Quality of life; $B M I$, body mass index; $C C I$, Charlson Comorbidity Index; $A S A$, American Society of Anesthesiologists; $U$, upper; $M$, middle; $c T N M$, clinical tumor-node-metastasis; $p T N M$, pathologic tumor-node-metastasis.

Survival is the critical measure for evaluation of treatment of malignant diseases. However, very few studies have reported on the survival of patients after MIE, especially on the basis of pathologic stage and in comparison with OE. In the 1011 cases of MIE (ESCC: 11\%; adenocarcinoma: $76 \%$ ) reported by Luketich and colleagues, ${ }^{1}$ the overall survival rates at 1 year, stratified by pathologic stage, were $86 \%$ (stage 0 ); $89 \%$ (stage I); $80 \%$ (stage IIa); $76 \%$ (stage IIb); 63\% (stage III); and 44\% (stage IV), as measured at the median follow-up of 20 months.

Nafteux and colleagues $^{18}$ reported a comparative analysis of MIE $(n=65)$ versus OE $(n=101)$ for early

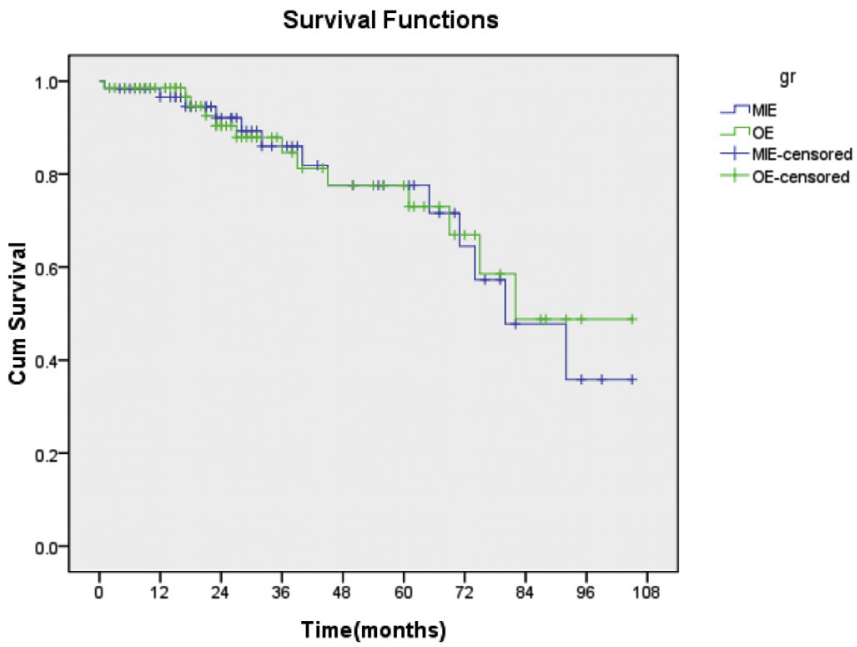

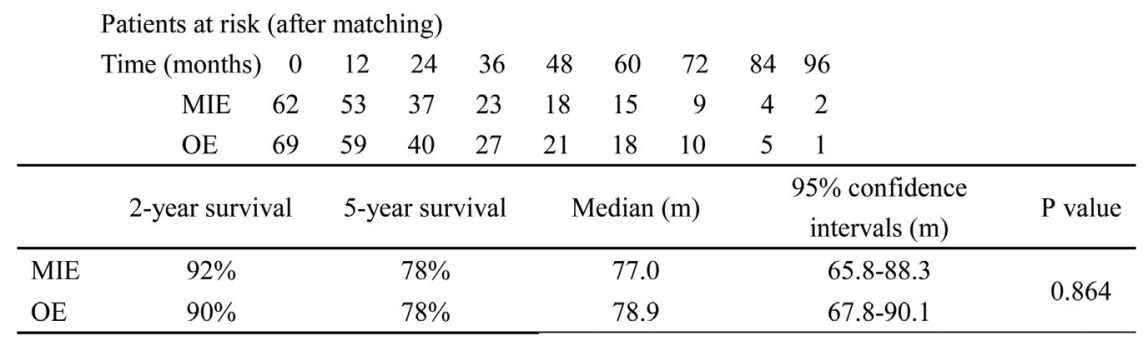

FIGURE 2. The survival curve of pathologic stage $0 \&$ I of the 2 groups, after matching. MIE, Minimally invasive esophagectomy; $O E$, open esophagectomy; cum, cumulative. 


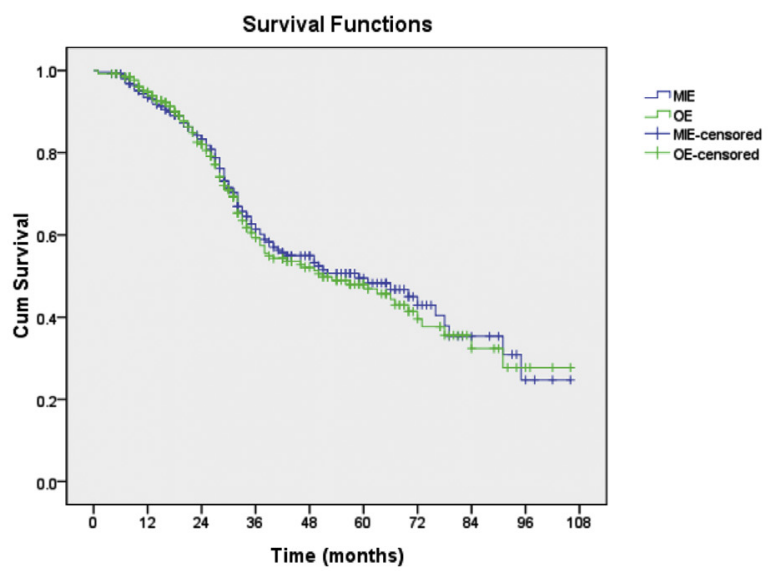

\begin{tabular}{|c|c|c|c|c|c|c|c|c|c|c|c|}
\hline \multicolumn{12}{|c|}{ Patients at risk (after matching) } \\
\hline & Time (months) & ) 0 & 12 & 24 & 36 & 48 & 60 & 72 & 84 & 96 & \\
\hline & MIE & 254 & 224 & 171 & 101 & 68 & 41 & 22 & 11 & 4 & \\
\hline & $\mathrm{OE}$ & 255 & 229 & 172 & 97 & 68 & 45 & 22 & 10 & 4 & \\
\hline \multicolumn{3}{|c|}{ 2-year survival } & \multicolumn{3}{|c|}{ 5-year survival } & \multicolumn{3}{|c|}{ Median (m) } & \multicolumn{2}{|c|}{$\begin{array}{c}95 \% \text { confidence } \\
\text { intervals }(\mathrm{m})\end{array}$} & $P$ value \\
\hline MIE & \multicolumn{2}{|l|}{$83 \%$} & \multicolumn{3}{|c|}{$50 \%$} & \multicolumn{2}{|c|}{59.0} & & \multicolumn{2}{|c|}{$38.7-79.3$} & \multirow{2}{*}{0.725} \\
\hline $\mathrm{OE}$ & \multicolumn{2}{|l|}{$82 \%$} & \multicolumn{3}{|c|}{$48 \%$} & \multicolumn{3}{|c|}{51.0} & \multicolumn{2}{|c|}{$32.5-69.5$} & \\
\hline
\end{tabular}

FIGURE 3. The survival curve of pathologic stage II of the 2 groups. MIE, Minimally invasive esophagectomy; $O E$, open esophagectomy; $c u m$, cumulative.

esophageal and gastroesophageal-junction carcinoma (adenocarcinoma was predominant in these cases, at $75 \%$ ): the 5-year cancer-specific and the recurrence-free survival, stratified to the pathologic T-stage, were similar. Lazzarino and colleagues ${ }^{19}$ reported the outcomes following MIE $(n=699)$ versus OE $(n=17,974)$ in

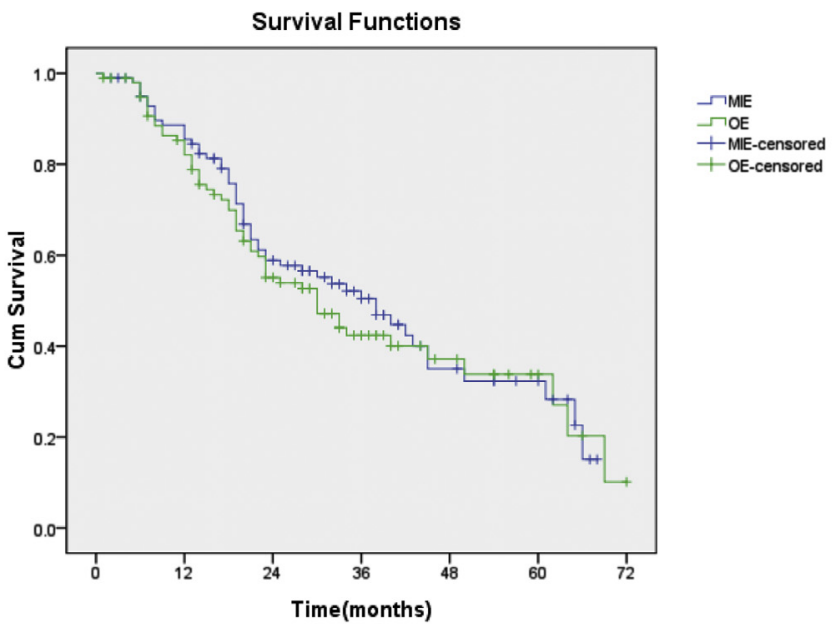

\begin{tabular}{|c|c|c|c|c|c|c|c|c|c|}
\hline \multicolumn{10}{|c|}{ Patients at risk (after matching) } \\
\hline & Time (months) & 0 & 12 & 24 & 36 & 48 & 60 & 72 & \\
\hline & MIE & 100 & 85 & 52 & 31 & 14 & 9 & 0 & \\
\hline & $\mathrm{OE}$ & 99 & 82 & 49 & 25 & 12 & 6 & 1 & \\
\hline \multicolumn{3}{|c|}{ 2-year survival } & \multicolumn{3}{|c|}{ 5-year survival } & \multicolumn{2}{|c|}{ Median (m) } & $\begin{array}{c}95 \% \text { confidence } \\
\text { intervals }(\mathrm{m})\end{array}$ & $P$ value \\
\hline MIE & \multicolumn{2}{|l|}{$59 \%$} & \multicolumn{3}{|c|}{$33 \%$} & \multicolumn{2}{|c|}{38.0} & $27.4-48.6$ & \multirow{2}{*}{0.592} \\
\hline $\mathrm{OE}$ & \multicolumn{2}{|l|}{$55 \%$} & \multicolumn{3}{|c|}{$34 \%$} & \multicolumn{2}{|c|}{30.0} & $20.4-39.6$ & \\
\hline
\end{tabular}

FIGURE 4. The survival curve of pathologic stage III of the 2 groups. MIE, Minimally invasive esophagectomy; $O E$, open esophagectomy; cum, cumulative. 


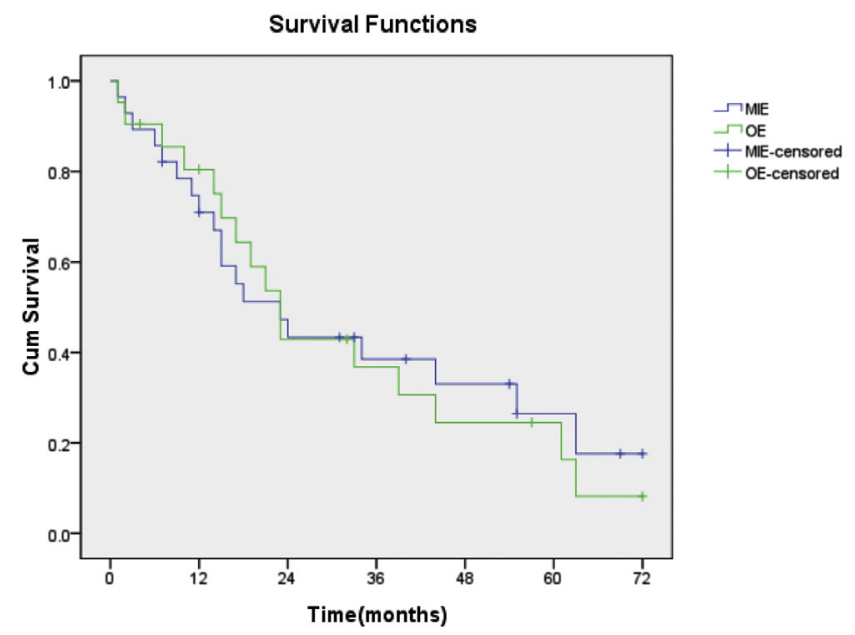

\begin{tabular}{|c|c|c|c|c|c|c|c|c|c|}
\hline \multicolumn{10}{|c|}{ Patients at risk (after matching) } \\
\hline & Time(months) & 0 & 12 & 24 & 36 & 48 & 60 & 72 & \\
\hline & MIE & 28 & 20 & 12 & 8 & 6 & 3 & 1 & \\
\hline & $\mathrm{OE}$ & 21 & 16 & 8 & 6 & 4 & 3 & 1 & \\
\hline \multicolumn{3}{|c|}{ 2-year survival } & \multicolumn{3}{|c|}{ 5-year survival } & \multicolumn{2}{|c|}{ Median (m) } & $\begin{array}{l}95 \% \text { confidence } \\
\text { intervals }(\mathrm{m})\end{array}$ & $P$ value \\
\hline MIE & \multicolumn{2}{|l|}{$43 \%$} & \multicolumn{3}{|c|}{$26 \%$} & \multicolumn{2}{|c|}{23.0} & $11.7-34.3$ & \multirow{2}{*}{0.802} \\
\hline $\mathrm{OE}$ & \multicolumn{2}{|l|}{$43 \%$} & \multicolumn{3}{|c|}{$25 \%$} & \multicolumn{2}{|c|}{23.0} & $6.2-39.8$ & \\
\hline
\end{tabular}

FIGURE 5. The survival curve of pathologic stage IV of the 2 groups. MIE, Minimally invasive esophagectomy; OE, open esophagectomy; cum, cumulative.

England from 1996 to 2008 and found that the 1-year survival with MIE was similar to that with OE (odds ratio $=0.68,95 \%$ confidence interval $=0.46-1.01$, $P=.058$ ). However, these reports were mainly from western countries with predominantly a histological type of adenocarcinoma. Further, in our series of ESCC, no statistically significant difference was found between the 2 groups, with stage-by-stage analysis.

Moreover, for malignant disease, such as esophageal cancer, which has high morbidity and a poor prognosis, survival alone may not adequately reflect the efficacy of treatment. Health-related QOL refers to patients' self-reported perception of their ability to live a useful and fulfilling life, ${ }^{20,21}$ which has been advocated by the U.S. Food and Drug Administration as the second-most relevant outcome measure to assess cancer therapy. However, very few studies have compared the impact of these 2 procedures on patients' postoperative QOL, especially for ESCC.

In the comparative analysis of MIE versus $\mathrm{OE}$ for early esophageal and gastroesophageal-junction cancer, conducted by Nafteux and colleagues, ${ }^{18}$ a statistically significant difference was found, favoring MIE, in the categories of role functioning and gastrointestinal pain in postoperative months 1 to 3 . In our series, much greater benefit of MIE was found for patients during the follow-up (especially within the first year of survival), confirmed by the multivariable regression model analysis mentioned earlier. However, the QOL, after 1 year and longer time intervals, found at these 2 centers was similar, including in a more recent and larger study from Nafteux and colleagues. ${ }^{22}$ Therefore, MIE seems to provide better QOL for patients with esophageal carcinoma, despite the diversity in histological type, tumor location, and race.

However, our study has limitations. It is retrospective and from only a single center. The selection of patients for MIE and $\mathrm{OE}$ was not a randomized procedure. Both of these study design features can lead to bias. Therefore, new prospective randomized controlled trials in multiple centers are needed to validate these findings.

\section{CONCLUSIONS}

In our experience, MIE is a safe and effective procedure for the treatment of ESCC. It may offer better perioperative outcomes, better postoperative QOL, as well as equal oncologic survival for patients, thereby providing an advantage in benefit to patients, compared with OE.

You can watch a Webcast of this AATS meeting presentation by going to: http://webcast.aats.org/2014/files/ Monday/20140428_300PM_320PM_Hao_Wang.mp4.

The authors thank Associate Professor Fang Fang (Department of Statistics, East China Normal University) for guidance on statistical analysis. 


\section{References}

1. Luketich JD, Pennathur A, Awais O, Levy RM, Keeley S, Shende M, et al. Outcomes after minimally invasive esophagectomy: review of over 1000 patients. Ann Surg. 2012;256:95-103.

2. Feng M, Shen Y, Wang H, Tan L, Zhang Y, Khan MA, et al. Thoracolaparoscopic esophagectomy: Is the prone position a safe alternative to the decubitus position? J Am Coll Surg. 2012;214:838-44.

3. Wang H, Tan L, Feng M, Zhang Y, Wang Q. Comparison of the short-term health-related quality of life in patients with esophageal cancer with different routes of gastric tube reconstruction after minimally invasive esophagectomy. Qual Life Res. 2011;20:179-89.

4. Wang H, Feng M, Tan L, Wang Q. Comparison of the short-term quality of life in patients with esophageal cancer after subtotal esophagectomy via video-assisted thoracoscopic or open surgery. Dis Esophagus. 2010;23:408-14.

5. Shen Y, Zhang Y, Tan L, Feng M, Wang H, Khan MA, et al. Extensive mediastinal lymphadenectomy during minimally invasive esophagectomy: optimal results from a single center. J Gastrointest Surg. 2012;16:715-21.

6. Shen Y, Feng M, Khan MA, Wang H, Tan L, Wang Q. A simple method minimizes chylothorax after minimally invasive esophagectomy. J Am Coll Surg. 2014;218:108-12.

7. Blazeby JM, Conroy T, Hammerlid E, Fayers P, Sezer O, Koller M. Clinical and psychometric validation of an EORTC questionnaire module, the EORTC QLQ-OES18, to assess quality of life in patients with esophageal cancer. Eur J Cancer. 2003;39:1384-94.

8. Nguyen NT, Hinojosa MW, Smith BR, Chang KJ, Gray J, Hoyt D. Minimally invasive esophagectomy: lessons learned from 104 operations. Ann Surg. 2008;248:1081-91.

9. Puntambekar SP, Agarwal GA, Joshi SN, Rayate NV, Sathe RM, Patil AM. Thoracolaparoscopy in the lateral position for esophageal cancer: the experience of a single institution with 112 consecutive patients. Surg Endosc. 2010;24: 2407-14.

10. Leibman S, Smithers BM, Gotley DC, Martin I, Thomas J. Minimally invasive esophagectomy: short- and long-term outcomes. Surg Endosc. 2006; 20:428-33.

11. Osugi H, Takemura M, Higashino M, Takada N, Lee S, Kinoshita H. A comparison of video-assisted thoracoscopic esophagectomy and radical lymph node dissection for squamous cell cancer of the oesophagus with open operation. Br J Surg. 2003;90:108-13.

12. Dolan JP, Kaur T, Diggs BS, Luna RA, Schipper PH, Tieu BH. Impact of comorbidity on outcomes and overall survival after open and minimally invasive esophagectomy for locally advanced esophageal cancer. Surg Endosc. 2013;27: 4094-103.

13. Zingg U, McQuinn A, DiValentino D, Esterman AJ, Bessell JR, Thompson SK, et al. Minimally invasive versus open esophagectomy for patients with esophageal cancer. Ann Thorac Surg. 2009;87:911-9.

14. Pennathur A, Luketich JD. Minimally invasive esophagectomy: short-term outcomes appear comparable to open esophagectomy. Ann Surg. 2012;255:206-7.

15. Schoppmann SF, Prager G, Langer FB, Riegler FM, Kabon B, Fleischmann E, et al. Open versus minimally invasive esophagectomy: a single-center case controlled study. Surg Endosc. 2010;24:3044-53.

16. Smithers BM, Gotley DC, Martin I, Thomas JM. Comparison of the outcomes between open and minimally invasive esophagectomy. Ann Surg. 2007;245: 232-40.

17. Biere SS, van Berge Henegouwen MI, Maas KW, Bonavina L, Rosman C, Garcia JR, et al. Minimally invasive versus open oesophagectomy for patients with oesophageal cancer: a multicentre, open-label, randomised controlled trial. Lancet. 2012;379:1887-92.

18. Nafteux P, Moons J, Coosemans W, Decaluwé H, Decker G, De Leyn P, et al. Minimally invasive oesophagectomy: a valuable alternative to open oesophagectomy for the treatment of early oesophageal and gastro-oesophageal junction carcinoma. Eur J Cardiothorac Surg. 2011;40:1455-63.

19. Lazzarino AI, Nagpal K, Bottle A, Faiz O, Moorthy K, Aylin P. Open versus minimally invasive esophagectomy: trends of utilization and associated outcomes in England. Ann Surg. 2010;252:292-8.

20. Courrech Staal EF, van Sandick JW, van Tinteren H, Cats A, Aaronson NK. Health-related quality of life in long-term esophageal cancer survivors after potentially curative treatment. J Thorac Cardiovasc Surg. 2010;140:777-83.

21. Safieddine N, Xu W, Quadri SM, Knox JJ, Hornby J, Sulman J, et al. Health-related quality of life in esophageal cancer: effect of neoadjuvant chemoradiotherapy followed by surgical intervention. J Thorac Cardiovasc Surg. 2009; 137:36-42.
22. Nafteux P, Durnez J, Moons J, Coosemans W, Decker G, Lerut T, et al. Assessing the relationships between health-related quality of life and postoperative length of hospital stay after oesophagectomy for cancer of the oesophagus and the gastro-oesophageal junction. Eur J Cardiothorac Surg. 2013;44:525-33.

\section{Discussion}

Dr A. Lerut (Leuven, Belgium). Thank you, Mr Chairman. I have no disclosures.

I congratulate Dr Wang and his group for a fine presentation, and excellent results. I also thank the authors for sending the article well in advance. I have a couple of comments and 3 questions. In this presentation, the authors compare a large series of minimally invasive esophagectomies with open esophagectomies, both performed in the same period of time. As a preliminary remark, I want to say that during my recent 2-month stay in Shanghai, at the Fudan Cancer Center, I was privileged to visit Dr Tan's group at Zhongshan Hospital, among other institutions, and I must say that I was impressed by these highly skilled surgeons working in a state-of-the-art operating theater complex, clearly explaining these outstanding, remarkable results. However, I also want to indicate some differences in the demographics of their patient population as compared with most centers in the Western Hemisphere, and in particular, our own minimally invasive esophagectomy series. Besides the fact that it deals only with squamous cell carcinoma, the average age of patients in this series is markedly younger, 56 years, as compared with 63 years, from our experience. The mean BMI was 22 in your series, versus 27 in ours, with $20 \%$ who had a BMI of $>30$ in our series. As to the comorbidities, the pulmonary comorbidity was $8 \%$ versus $13 \%$; cardiac was $6 \%$ versus $17 \%$; and ASA III score, was $4 \%$ versus the $19 \%$ from our experience. In your series, as described in the article, you excluded all previous abdominal and thoracic surgery, which today, in our experience, is nearly $20 \%$. Here are my 3 questions, and I will ask each one separately so you can answer after each question. You mentioned perioperative mortality, but I would like to know what your definition is of perioperative mortality, in the sense that, today, there is a growing tendency to provide 90-day mortality as the real figure, rather than 30-day mortality. Did you look at 90-day mortality? Was your figure 30-day mortality? Can you comment on this?

Dr Wang. Thank you. We defined the perioperative mortality in this study as 30-day mortality. The reason we used this parameter is that we wanted to compare it with other previously published results in the literatures. Maybe 90-day mortality is a better parameter, and we will use it in our future papers.

Dr Lerut. Thank you. I encourage everybody in the audience to use 90-day mortality in the future because it is just simply doubling as compared with 30-day mortality, and that is important in your discussions with patients. My second question relates to the anastomotic leaks. You have in the minimally invasive esophagectomy group an anastomotic leak rate of $12.2 \%$, which is more than double the $5.8 \%$ leak rate in the open group. Do you have an explanation for this quite high incidence of leaks in the MIE group as compared with the open group? Did you use a different technique for the conduit construction and the anastomotic construction? Could you comment on this, please?

Dr Wang. I think that there are 2 reasons. In the MIE group, cervical anastomosis was performed in 720 patients, and 
intrathoracic anastomosis was performed in only 7 patients. In the open group, cervical anastomosis was performed in nearly half of the patients, and intrathoracic anastomosis was performed in the other half. As we know, the leak rate in cervical anastomosis is usually higher than it is in intrathoracic anastomosis. Maybe that is 1 of the reasons. Another reason may be the learning curve. As we do laparoscopy in the early stage, immature skills often lead to the injury of the stomach and decrease the blood supply for the anastomosis. In that time, the cervical anastomosis leak rate was about $20 \%$; as skills improved, the stomach was better protected, and the leak rate at present has decreased to approximately $5 \%$.

Dr Lerut. Thank you. From your article, I noticed that in the series with MIE, you had 63 patients who underwent what I would call a hybrid intervention, in that they received a formal laparotomy instead of a laparoscopy. In this subset, what were the scores for quality of life over time for physical functioning, fatigue, pain, dyspnea, and global quality? Were they more like the results you had in open surgery for these parameters, or were they the same as in the other patients who had a formal laparoscopy?

Dr Wang. In this series, my impression is that the hybrid patients had almost the same quality of life as the MIE patients. As I know from the literature, the benefit of laparoscopy for esophagectomy is controversial, and in my opinion, the thoracoscopy may contribute much more to the benefit of MIE.

Dr Lerut. Along that line, to finish, I noticed in your article that 118 patients had neoadjuvant upfront induction therapy, and again, my question is whether you have looked at the same quality-of-life scores for this subset for over time? Were there any differences in this group versus the group who had minimally invasive esophagectomies without induction therapy?
Dr Wang. Do you mean the patients who received neoadjuvant therapy?

Dr Lerut. Yes.

Dr Wang. Yes. In our experience, the patients who received neoadjuvant therapy usually had a lower quality of life. However, the patients whose status was too low would not have been included in the surgery, so in my opinion, the decrease in quality of life was not severe in this series. On the other hand, the rates of neoadjuvant therapy in the 2 groups were similar, so the 2 groups had similar quality of life at baseline.

Dr Lerut. Thank you. I also thank the association for the privilege of discussing this paper.

Dr Wang. Thank you very much.

Dr B. Meyers (St. Louis, Mo). Congratulations on an excellent presentation. I particularly commend you on giving your results for the entire series, including the very early patients. It would have been tempting, and we would have totally understood, if you had just shown the last 500 patients and maybe omitted the early patients that were on your learning curve. Your outcomes would have looked better, but we would not have learned as much as we did by your showing the graded approach you took with the airway management, and the improvement of your results over time.

You had a very low rate of chylothorax, and I was interested and impressed by the fact that you gave the patients milk 6 hours before the operation. Maybe you could comment about that? Did you do that for all of the patients, or did you start part way through this series of 790 patients to give the milk before surgery, to help identify and fix the chylothorax during the primary procedure?

Dr Wang. Oral intake of whole milk is used to facilitate the exposure of the thoracic duct in the operation. We have used this method for approximately 5 years. Thank you.

Readers who found these articles interesting may also like to read the following papers found in recent and future issues of our sister publications, Seminars in Thoracic and Cardiovascular Surgery and Operative Techniques in Thoracic and Cardiovascular Surgery!

Otis Rickman. Electromagnetic Navigation Assisted Bronchoscopy. Oper Tech Thorac Cardiovasc Surg. Summer 2014;19(2):199-218.

Eric Grogan. Localization techniques for small lung nodules. Oper Tech Thorac Cardiovasc Surg. Summer 2014;19(2):179-198. Donald Nuss. The Minimally Invasive Repair of Pectus Excavatum. Oper Tech Thorac Cardiovasc Surg. Summer 2014; 9(2):199-218. John Kucharczuk. Total Pectus Excavatum Repair: Open Approach. Oper Tech Thorac Cardiovasc Surg. Expected publication February 2015. 
TABLE E1. The logistic regression analysis for propensity-score matching

\begin{tabular}{|c|c|c|c|c|c|}
\hline Parameters & Estimation & SD & $\chi^{2}$ & $P$ value & OR $(95 \%$ CI $)$ \\
\hline Intercept & 11.58 & 1.23 & 87.94 & $<.0001$ & - \\
\hline Age & -0.23 & 0.02 & 122.72 & $<.0001$ & $0.80(0.77,0.83)$ \\
\hline BMI & 0.04 & 0.02 & 2.60 & .11 & $1.04(0.99,1.08)$ \\
\hline Historical period of surgery $=1($ of 3$)$ & -1.09 & 0.14 & 63.28 & $<.0001$ & $0.10(0.06,0.18)$ \\
\hline Historical period of surgery $=2($ of 3$)$ & -0.10 & 0.09 & 1.39 & .24 & $0.27(0.18,0.42)$ \\
\hline $\operatorname{Sex}=1($ of 2$)$ & 0.01 & 0.07 & 0.01 & .91 & $1.02(0.76,1.36)$ \\
\hline $\mathrm{CCI}=0($ of 6$)$ & -3.24 & 0.91 & 12.78 & .00 & $0.01(<0.001,0.20)$ \\
\hline $\mathrm{CCI}=1($ of 6$)$ & -1.33 & 0.40 & 11.22 & .00 & $0.06(0.01,0.71)$ \\
\hline $\mathrm{CCI}=2($ of 6$)$ & 0.03 & 0.34 & 0.01 & .93 & $0.22(0.02,2.61)$ \\
\hline $\mathrm{CCI}=3($ of 6$)$ & 0.37 & 0.33 & 1.23 & .27 & $0.32(0.03,3.61)$ \\
\hline $\mathrm{CCI}=4($ of 6$)$ & 1.46 & 0.36 & 16.08 & $<.0001$ & $0.94(0.08,10.36)$ \\
\hline $\mathrm{CCI}=5($ of 6$)$ & 1.19 & 0.69 & 2.99 & .08 & $0.72(0.10,5.08)$ \\
\hline ASA grade $=1($ of 3$)$ & -0.02 & 0.32 & 0.00 & .95 & $1.03(0.19,5.47)$ \\
\hline ASA grade $=2($ of 3$)$ & 0.07 & 0.28 & 0.06 & .81 & $1.12(0.23,5.50)$ \\
\hline Tumor location = 1 (of 3$)$ & -0.02 & 0.11 & 0.04 & .85 & $0.98(0.68,1.41)$ \\
\hline Tumor location $=2($ of 3$)$ & 0.02 & 0.08 & 0.09 & .77 & $1.03(0.80,1.33)$ \\
\hline Neoadjuvant therapy $=0($ of 2$)$ & 0.20 & 0.19 & 1.07 & .30 & $1.29(0.73,2.28)$ \\
\hline Neoadjuvant therapy $=1$ (of 2) & -0.14 & 0.20 & 0.48 & .49 & $0.93(0.51,1.68)$ \\
\hline $\mathrm{cTNM}=1($ of 4$)$ & -0.66 & 0.48 & 1.95 & .16 & $0.27(0.04,1.64)$ \\
\hline $\mathrm{cTNM}=2($ of 4$)$ & -0.52 & 0.40 & 1.74 & .19 & $0.31(0.06,1.62)$ \\
\hline $\mathrm{cTNM}=3($ of 4$)$ & 0.53 & 0.40 & 1.80 & .18 & $0.89(0.41,1.92)$ \\
\hline $\mathrm{pTNM}=1($ of 4$)$ & 0.97 & 0.60 & 2.63 & .10 & $3.93(0.74,20.88)$ \\
\hline $\mathrm{pTNM}=2($ of 4$)$ & -0.30 & 0.25 & 1.44 & .23 & $1.11(0.53,2.31)$ \\
\hline pTNM $=3($ of 4$)$ & -0.26 & 0.27 & 0.94 & .33 & $1.15(0.68,1.95)$ \\
\hline
\end{tabular}

The C-statistic of our model is 0.70. OR, Odds ratio; CI, confidence interval; BMI, body mass index; CCI, Charlson Comorbidity Index; ASA, American Society of Anesthesiologists; $c T N M$, clinical tumor-node-metastasis; $p T N M$, pathologic tumor-node-metastasis; $S D$, standard deviation. 
TABLE E2. Assessment of QOL (after matching)

\begin{tabular}{|c|c|c|c|}
\hline Variable & $\operatorname{MIE}(n=444)$ & OE $(n=444)$ & $P$ value \\
\hline \multicolumn{4}{|l|}{ Global QOL } \\
\hline Baseline & $72.8 \pm 10.6$ & $73.0 \pm 10.9$ & .860 \\
\hline $1 \mathrm{mo}$ & $55.7 \pm 12.4$ & $40.1 \pm 9.2$ & $<.001$ \\
\hline $3 \mathrm{mo}$ & $66.2 \pm 13.0$ & $42.6 \pm 14.1$ & $<.001$ \\
\hline $6 \mathrm{mo}$ & $68.5 \pm 11.6$ & $54.0 \pm 15.0$ & $<.001$ \\
\hline $12 \mathrm{mo}$ & $70.5 \pm 13.3$ & $64.7 \pm 10.4$ & $<.001$ \\
\hline $18 \mathrm{mo}$ & $72.1 \pm 13.0$ & $71.2 \pm 12.7$ & .116 \\
\hline 24 mo & $72.5 \pm 13.9$ & $71.2 \pm 13.4$ & .341 \\
\hline \multicolumn{4}{|c|}{ Physical function } \\
\hline Baseline & $84.8 \pm 10.6$ & $84.7 \pm 9.0$ & .960 \\
\hline $1 \mathrm{mo}$ & $66.8 \pm 9.2$ & $47.4 \pm 8.1$ & $<.001$ \\
\hline $3 \mathrm{mo}$ & $72.0 \pm 11.1$ & $49.3 \pm 9.7$ & $<.001$ \\
\hline $6 \mathrm{mo}$ & $77.1 \pm 12.1$ & $49.3 \pm 9.7$ & $<.001$ \\
\hline $12 \mathrm{mo}$ & $78.8 \pm 12.3$ & $71.6 \pm 13.3$ & $<.001$ \\
\hline $18 \mathrm{mo}$ & $80.4 \pm 9.0$ & $78.4 \pm 10.4$ & .028 \\
\hline $24 \mathrm{mo}$ & $80.8 \pm 6.1$ & $80.3 \pm 7.5$ & .492 \\
\hline \multicolumn{4}{|c|}{ Fatigue symptoms } \\
\hline Baseline & $21.8 \pm 12.5$ & $21.6 \pm 11.2$ & .566 \\
\hline $1 \mathrm{mo}$ & $44.2 \pm 14.2$ & $56.8 \pm 16.7$ & $<.001$ \\
\hline $3 \mathrm{mo}$ & $40.3 \pm 14.3$ & $54.9 \pm 15.0$ & $<.001$ \\
\hline $6 \mathrm{mo}$ & $33.3 \pm 14.0$ & $46.1 \pm 15.5$ & $<.001$ \\
\hline $12 \mathrm{mo}$ & $26.9 \pm 13.0$ & $31.2 \pm 10.8$ & $<.001$ \\
\hline $18 \mathrm{mo}$ & $26.7 \pm 7.9$ & $27.2 \pm 7.7$ & .424 \\
\hline $24 \mathrm{mo}$ & $26.4 \pm 7.4$ & $26.8 \pm 7.1$ & .501 \\
\hline \multicolumn{4}{|c|}{ Pain symptoms } \\
\hline Baseline & $15.2 \pm 8.0$ & $15.6 \pm 8.0$ & .476 \\
\hline $1 \mathrm{mo}$ & $34.8 \pm 13.8$ & $62.7 \pm 13.9$ & $<.001$ \\
\hline $3 \mathrm{mo}$ & $30.8 \pm 10.7$ & $50.7 \pm 12.5$ & $<.001$ \\
\hline $6 \mathrm{mo}$ & $28.5 \pm 11.6$ & $36.6 \pm 9.7$ & $<.001$ \\
\hline $12 \mathrm{mo}$ & $25.4 \pm 11.7$ & $26.1 \pm 8.0$ & .019 \\
\hline $18 \mathrm{mo}$ & $24.7 \pm 10.8$ & $25.1 \pm 12.3$ & .411 \\
\hline $24 \mathrm{mo}$ & $24.3 \pm 11.1$ & $24.3 \pm 9.1$ & .792 \\
\hline \multicolumn{4}{|c|}{ Dyspnea symptoms } \\
\hline Baseline & $10.7 \pm 7.1$ & $10.5 \pm 6.8$ & .738 \\
\hline $1 \mathrm{mo}$ & $23.3 \pm 7.3$ & $34.5 \pm 9.9$ & $<.001$ \\
\hline $3 \mathrm{mo}$ & $20.9 \pm 7.5$ & $25.7 \pm 8.5$ & $<.001$ \\
\hline $6 \mathrm{mo}$ & $18.9 \pm 6.9$ & $21.5 \pm 8.6$ & $<.001$ \\
\hline $12 \mathrm{mo}$ & $17.4 \pm 6.7$ & $18.0 \pm 6.4$ & .181 \\
\hline $18 \mathrm{mo}$ & $16.8 \pm 7.6$ & $17.3 \pm 6.6$ & .604 \\
\hline $24 \mathrm{mo}$ & $16.9 \pm 6.2$ & $17.1 \pm 5.7$ & .820 \\
\hline
\end{tabular}

$P$ values were determined by Mann-Whitney $U$ test. A higher score on global QOL and physical function represents better QOL status, whereas a higher score on fatigue, pain, and dyspnea symptoms indicates worse QOL status. $Q O L$, Quality of life; MIE, minimally invasive esophagectomy; $O E$, open esophagectomy. 
TABLE E3. Analysis of QOL (generalized estimating equation) in detail

\begin{tabular}{|c|c|c|c|c|}
\hline & Estimate & Standard error & Wald statistics & $P$ value \\
\hline \multicolumn{5}{|l|}{ (1) Global QOL } \\
\hline Intercept & -20.946 & 4.093 & 26.190 & $<.001$ \\
\hline Age & -0.205 & 0.084 & 5.976 & .015 \\
\hline Sex & -0.234 & 0.636 & 0.136 & .712 \\
\hline BMI & -0.117 & 0.097 & 1.467 & .226 \\
\hline $\mathrm{CCI}$ & 0.572 & 0.451 & 1.610 & .205 \\
\hline ASA grade & -0.817 & 0.734 & 1.240 & .266 \\
\hline Tumor location (U) & 0.086 & 0.757 & 0.013 & .909 \\
\hline Tumor location (M) & 0.620 & 0.551 & 1.268 & .260 \\
\hline Neoadjuvant chemotherapy & -2.858 & 1.181 & 5.851 & .016 \\
\hline Neoadjuvant chemoradiotherapy & 0.302 & 0.948 & 0.101 & .750 \\
\hline cTNM stage & 0.918 & 0.685 & 1.796 & .180 \\
\hline pTNM stage & -0.712 & 0.657 & 1.174 & .279 \\
\hline Historical period of surgery & -0.349 & 0.566 & 0.381 & .537 \\
\hline Surgical approach & 19.506 & 0.616 & 1003.639 & $<.001$ \\
\hline Length of postoperative time & 1.656 & 0.064 & 672.271 & $<.001$ \\
\hline \multicolumn{5}{|l|}{ (2) Physical function } \\
\hline Intercept & -32.937 & 2.970 & 122.967 & $<.001$ \\
\hline Age & -0.079 & 0.060 & 1.748 & .186 \\
\hline Sex & -0.232 & 0.494 & 0.221 & .639 \\
\hline BMI & -0.054 & 0.075 & 0.512 & .474 \\
\hline $\mathrm{CCI}$ & -0.035 & 0.367 & 0.009 & .924 \\
\hline ASA grade & -0.519 & 0.595 & 0.760 & .383 \\
\hline Tumor location (U) & 0.391 & 0.580 & 0.453 & .501 \\
\hline Tumor location (M) & 0.306 & 0.440 & 0.485 & .486 \\
\hline Neoadjuvant chemotherapy & -1.119 & 1.061 & 1.112 & .292 \\
\hline Neoadjuvant chemoradiotherapy & 0.571 & 0.703 & 0.660 & .417 \\
\hline cTNM stage & 0.675 & 0.519 & 1.686 & .194 \\
\hline pTNM stage & -0.321 & 0.459 & 0.489 & .484 \\
\hline Historical period of surgery & -0.228 & 0.423 & 0.291 & .590 \\
\hline Surgical approach & 21.742 & 0.524 & 1721.569 & $<.001$ \\
\hline Length of postoperative time & 1.624 & 0.020 & 6722.664 & $<.001$ \\
\hline \multicolumn{5}{|l|}{ (3) Fatigue symptoms } \\
\hline Intercept & 24.927 & 3.477 & 51.386 & $<.001$ \\
\hline Age & 0.076 & 0.076 & 1.014 & .314 \\
\hline Sex & -0.306 & 0.631 & 0.235 & .627 \\
\hline BMI & 0.016 & 0.082 & 0.040 & .841 \\
\hline $\mathrm{CCI}$ & -0.068 & 0.421 & 0.026 & .871 \\
\hline ASA grade & 0.383 & 0.699 & 0.301 & .583 \\
\hline Tumor location (U) & -0.028 & 0.636 & 0.002 & .965 \\
\hline Tumor location (M) & 0.066 & 0.521 & 0.016 & .900 \\
\hline Neoadjuvant chemotherapy & 1.850 & 1.021 & 3.282 & .070 \\
\hline Neoadjuvant chemoradiotherapy & -0.690 & 0.997 & 0.479 & .489 \\
\hline cTNM stage & 0.664 & 0.661 & 1.010 & .315 \\
\hline pTNM stage & -0.299 & 0.575 & 0.270 & .603 \\
\hline Historical period of surgery & 0.227 & 0.552 & 0.168 & .682 \\
\hline Surgical approach & -10.599 & 0.850 & 155.531 & $<.001$ \\
\hline Length of postoperative time & -1.292 & 0.034 & 1432.795 & $<.001$ \\
\hline \multicolumn{5}{|l|}{ (4) Pain symptoms } \\
\hline Intercept & 38.952 & 2.586 & 226.926 & $<.001$ \\
\hline Age & -0.012 & 0.054 & 0.052 & .820 \\
\hline Sex & -0.618 & 0.440 & 1.973 & .160 \\
\hline BMI & -0.027 & 0.060 & 0.200 & .654 \\
\hline CCI & 0.136 & 0.298 & 0.210 & .647 \\
\hline ASA grade & 0.181 & 0.479 & 0.143 & .706 \\
\hline
\end{tabular}


TABLE E3. Continued

\begin{tabular}{|c|c|c|c|c|}
\hline & Estimate & Standard error & Wald statistics & $P$ value \\
\hline Tumor location (U) & 0.148 & 0.538 & 0.076 & .783 \\
\hline Tumor location (M) & -0.437 & 0.370 & 1.397 & .237 \\
\hline Neoadjuvant chemotherapy & 1.436 & 0.776 & 3.424 & .064 \\
\hline Neoadjuvant chemoradiotherapy & -0.538 & 0.601 & 0.803 & .370 \\
\hline cTNM stage & 0.087 & 0.487 & 0.032 & .858 \\
\hline pTNM stage & 0.413 & 0.428 & 0.930 & .335 \\
\hline Historical period of surgery & 0.511 & 0.393 & 1.690 & .194 \\
\hline Surgical approach & -21.537 & 0.414 & 2708.927 & $<.001$ \\
\hline Length of postoperative time & -1.567 & 0.030 & 2745.508 & $<.001$ \\
\hline \multicolumn{5}{|l|}{ (5) Dyspnea symptoms } \\
\hline Intercept & 13.736 & 1.749 & 61.691 & $<.001$ \\
\hline Age & 0.025 & 0.036 & 0.493 & .483 \\
\hline Sex & -0.467 & 0.283 & 2.719 & .099 \\
\hline BMI & 0.056 & 0.041 & 1.916 & .166 \\
\hline $\mathrm{CCI}$ & -0.444 & 0.202 & 4.858 & .028 \\
\hline ASA grade & 1.170 & 0.334 & 12.278 & $<.001$ \\
\hline Tumor location (U) & 0.622 & 0.351 & 3.139 & .076 \\
\hline Tumor location (M) & -0.004 & 0.252 & 0.000 & .989 \\
\hline Neoadjuvant chemotherapy & -0.112 & 0.548 & 0.041 & .839 \\
\hline Neoadjuvant chemoradiotherapy & 0.137 & 0.398 & 0.119 & .730 \\
\hline cTNM stage & 0.515 & 0.351 & 2.153 & .142 \\
\hline pTNM stage & -0.255 & 0.323 & 0.622 & .430 \\
\hline Historical period of surgery & -0.133 & 0.279 & 0.226 & .634 \\
\hline Surgical approach & -6.677 & 0.479 & 194.276 & $<.001$ \\
\hline Length of postoperative time & -0.221 & 0.041 & 28.450 & $<.001$ \\
\hline
\end{tabular}

Bold indicates statistical significance $(P<.05)$. $Q O L$, Quality of life; $B M I$, body mass index; $C C I$, Charlson Comorbidity Index; $A S A$, American Society of Anesthesiologists; $U$, upper; $M$, middle; $c T N M$, clinical tumor-node-metastasis; $p T N M$, pathologic tumor-node-metastasis. 